\title{
PERBANDINGAN pARTIKEL PREPOSISI BAHASA INDONESIA DENGAN BAHASA KOREA, SEBUAH ANALISIS KONTRASTIF
}

\author{
AULIA NURNOVIKA \\ Universitas Negeri Jakarta, Indonesia \\ aulianurnovika@gmail.com \\ Pertama Diterima: 9 Juli 2018 \\ Bukti Akhir Diterima: 3 Juni 2019

\begin{abstract}
Abstrak
Penelitian kontrastif tentang partikel preposisi bahasa Indonesia dan bahasa Korea ini membahas persamaan dan perbedaan kedua bahasa dari beberapa aspek, yaitu (1) bentuk; (2) posisi, (3) fungsi, dan (4) penggunaan. Adapun metode penelitian yang digunakan dalam proses pengumpulan data ini adalah metode deskriptif kontrastif. Metode ini merupakan metode gabungan yang bertujuan mendeskripsikan bahasa Indonesia dan bahasa Korea yang dikontraskan. Pengontrasan dilakukan untuk memperoleh informasi tentang persamaan dan perbedaan karakteristik gramatikal di antara kedua bahasa tersebut. Hasil yang diperoleh dari analisis data menunjukkan bahwa (1) Bentuk partikel preposisi dari kedua bahasa berbeda. Bahasa Indonesia partikelnya berupa kata sedangkan bahasa korea partikelnya berupa satuan yang lekat atau morfem. (2) Posisi partikel preposisi dalam bahasa Indonesia umumnya terdapat di depan kata yang diterangkan sedangkan partikel preposisi dalam bahasa Korea pasti lekat dibelakang kata yang diterangkannya. (3) Fungsi partikel preposisi dalam bahasa Indonesia berjumlah 16 sedangkan fungsi partikel preposisi dalam bahasa Korea berjumlah 11. (4) Penggunaan partikel preposisi
\end{abstract} \\ dalam kedua bahasa sama-sama berperan aktif dalam pembentukan kalimat.
}

Kata Kunci: analisis kontrastif, partikel preposisi, bahasa Indonesia, bahasa Korea

\begin{abstract}
The study of contrastive about preposition particles of Indonesian and Korean language discusses the similarities and differences of the two languages from several aspects, namely (1) form; (2) position, (3) function, and (4) usage. The research method used in this data collection process is a descriptive method contrastive. This method is a joint method that aims to describe the Indonesian language and the Korean language that is contrasted. Contrast is performed to obtain information on the similarities and differences in grammatical characteristics between the two languages.The results obtained from data analysis show that (1) Form of preposition particles of two different languages. Bahasa Indonesia partikelnya word while the korean particles in the form of a unit that is sticky or morpheme. (2) The position of the preposition particles in the Indonesian language is generally present in front of the said word whereas the preposition particles in Korean must be attached behind the word it describes. (3) The function of the preposition particles in Indonesian is 16, whereas the function of preposition particles in Korean is 11. (4) The use of preposition particles in both languages is equally active in the formation of sentences.
\end{abstract}

Keywords: contrastive analysis, preposition particles, Indonesian language, Korean language 


\section{PENDAHULUAN}

Pendidikan bahasa Korea di Indonesia semakin banyak peminatnya seiring berkembangnya hubungan antarkedua negara. Tidak bisa dilupakan pula bahwa setakat ini sudah terdapat pendidikan bahasa Indonesia di Korea. Bertolak pada kenyataan tersebut, maka diperlukan pengetahuan yang mumpuni terkait kedua bahasa agar seorang pemelajar mampu menggunakan bahasa Indonesia maupun bahasa Korea dengan baik.

Pada dasarnya bahasa Indonesia (BI) dan bahasa Korea (BK) sama-sama merupakan bahasa aglutinatif. Oleh karena itu tidak terlalu tampak perbedaan di antara kedua bahasa tersebut. Namun demikian, bila ditinjau lebih dalam kajian antara kedua bahasa tersebut, selain pada tataran kalimat, pada tataran kata pun dapat ditemukan banyak perbedaan. Perbedaan ini dilihat dari bentuk, fungsi, serta penggunaan kata itu sendiri.

Konsep kata yang umum kita jumpai dalam berbagai buku linguistic adalah bahwa kata merupakan bentuk yang, ke dalam mempunyai susunan fonologi yang stabil dan tidak berubah, dan keluar mempunyai kemungkinan mobilitas di dalam kalimat. Chaer (2015:63) mengatakan kata diklasifikasikan ke dalam dua kelas, yakni kelas terbuka dan kelas tertutup. Kelas terbuka adalah kelas yang keanggotaannya dapat bertambah atau berkurang sewaktu-waktu berkenaan dengan perkembangan social budaya yang terjadi dalam masyarakat penutur suatu bahasa. Lain halnya dengan kelas tertutup yang merupakan kelas kata yang jumlah keanggotaannya terbatas dan tidak tampak kemungkinan untuk bertambah atau berkurang.

Dalam penggunaannya, kelas kata terbuka tentu lebih sering digunakan. Namun, kelas kata tertutup juga memiliki peran penting. Kelas kata tertutup ini juga dapat diartikan sebagai kelas Kata Tugas (KT) atau Partikel. Partikel berfungsi menghubungkan kata, frase, klausa, atau kalimat dan menunjukkan sifat hubungan di antara unsur-unsur yang dihubungkan itu, Kentjono et al (2010:192).

Pada umumnya, partikel tidak mempunyai makna leksikal. Partikel hanya memiliki makna gramatikal, yakni makna yang baru muncul setelah digunakan atau diiringi kata lain. Partikel terdiri atas tujuh kelompok: (1) Kata Depan (preposisi), (2) Kata Penghubung (konjungsi), (3) Kata Keterangan (adverbia), (4) Kata Tanya, (5) Kata Sandang (artikula), (6) Kata Seru, dan (7) Kata Perujuk. Pada penelitian ini hanya akan dibahas partikel preposisi.

Preposisi atau Kata Depan merupakan suatu jenis Kata Tugas yang bertugas menandai hubungan makna antarkata, atau antarkelompok kata dalam kalimat. Preposisi tidak menghubungkan klausa dengan klausa dalam kalimat. Preposisi hanya menandai hubungan antarkata dan antarkelompok kata dalam kalimat. Akan tetapi, preposisi menandai hubungan bagian-bagian kalimat, baik yang berupa kata maupun kelompok kata (frase). Sebagian besar preposisi diikuti Kata Benda (Nomina), namun sebenarnya preposisi dapat pula diikuti Kata Kerja (Verba) dan Kata Sifat (Adjektiva).

Perbedaan bahasa Indonesia dan bahasa Korea paling utama terletak pada tulisannya. Bahasa Indonesia menggunakan abjad atau alphabet sedangkan bahasa Korea menggunakan huruf Hangeul. Mempelajari bahasa asing juga berarti mempelajari makna. Dengan adanya perbedaan makna kata antara BI dan BK, hal ini memberikan kendala dan kesulitan bagi pemelajar asing BI maupun BK 
dalam mempelajari bahasa target.fenomena tersebut di atas, meupakan hal yang tdak jarang terjadi dalam pembelajaran bahasa kedua, sehingga sangat dibutuhkan solusi yang tepat untuk pemerolehan dan pembelajarannya. Kesalahan penggunaan dapat terjadi bila pemahaman terhadap makna dan penggunaan belum terjadi secara utuh.

Oleh karena itu, dalam menyikapi peermasalahan tersebut di atas, akan dilakukan penelitian yang hanya membandingkan atau mengkontraskan karakteristik gramatikal BI dan BK dalam penggunaan salah satu KT atau Partikel yakni preposisi. Perbedaan ini dapat dilihat dari bentuk, fungsi, hingga penggunaan partikel preposisi tersebut dalam kalimat.penelitian semacam ini dikenal dengan sebutan analisis kontrastif. Lado (1975) dalam teorinya mengatakan bahwa analisis kontrastif merupakan sebuah cara untuk mendeskripsikan kesulitan atau kemudahan pembelajar dalam belajar bahasa kedua dan bahasa asing. Penelitian ini sangat penting dilakukan mengingat sebelumnya belum pernah ada penelitian serupa.

Hasil penelitian ini akan menjadi informasi penting bagi pendidik dan peserta didik BI maupun BK dalam memahami masing-masing karakteristik gramatikal partikel preposisi dalam penggunaannya pada kalimat sebagaimana telah disebutkan di atas, sehingga dapat memberikan kemudahan bagi pendidik untuk mengajarkan bahasa kedua, sekaligus dalam menghadapi kesulitan yang dialami oleh peserta didik.

Di samping itu, hal ini juga menjadi cerminan gramatikal tersendiri antara BI dan BK bagi peserta didik pada khususnya, yang nantinya akan mampu membantu memberikan pemahaman yang komprehensif kepada mereka dalam pembelajaran gramatikal, karena dituntun oleh hasil analisis kontrastif BI dan BK. Hal itu juga berpijak pada pernyataan bahwa Kajian kontrastif merupakan referensi terbaik bagi para pendidik bahasa target untuk mengantisipasi kesulitan dan kesalahan yang dihadapi peserta didiknya, Fries (1945) dan Gleason (1961).

\section{METODE PENELITIAN}

Pendekatan yang digunakan ialah pendekatan kualitatif studi pustaka, yaitu penelitian yang didasarkan pada sumber-sumber pustaka yang ada untuk kemudian diananalis. Metode penelitian yang digunakan dalam penelitian ini adalah analisis deskriptif kontrastif. Metode ini merupakan penggabungan dari metode analisis deskriptif dan metode analisis kontrastif. Pada penelitian ini, metode analisis deskriptif kontrastif digunakan untuk menggambarkan serta menganalisis persamaan dan perbedaan bahasa Indonesia dengan bahasa Korea. Penjelasan mengenai persamaan dan perbedaan tersebut, akan menjelaskan karakteristik penggunaan partikel preposisi pada kedua bahasa.

\section{HASIL PENELITIAN DAN PEMBAHASAN}

\section{Partikel Preposisi Bahasa Indonesia}

Berdasarkan bentuknya, preposisi dikelompokkan atas preposisi tunggal dan preposisi gabungan. Preposisi tunggal terdiri atas preposisi dasar dan preposisi berafiks, sedangkan preposisi 
gabungan terdiri atas preposisi berdampingan, preposisi terbagi, dan preposisi berulang. Daftar kata terdapat pada bagan berikut.

Tabel 1. Preposisi

\begin{tabular}{|c|c|c|c|c|}
\hline \multicolumn{2}{|c|}{ Preposisi Tunggal } & \multicolumn{3}{|c|}{ Preposisi Gabungan } \\
\hline Preposisi dasar & Preposisi berafiks & $\begin{array}{c}\text { Preposisi } \\
\text { berdampingan }\end{array}$ & Preposisi terbagi & Preposisi berulang \\
\hline Akan & Bersama & Daripada & Antara ... dengan & Gara-gara \\
\hline Antar & Beserta & Kepada & Antara ... dan & \\
\hline Antara & Menjelang & Oleh karena & Dari ... hingga & \\
\hline Bagi & Menuju & Oleh sebab & Dari ... sampai & \\
\hline Buat & Menurut & Sampai ke & Dari ... sampai ke & \\
\hline Dari & Seantero & Sampai dengan & Sejak ... hingga & \\
\hline Demi & Sekeliling & Selain dari & Sejak ... sampai & \\
\hline Dengan & Sekitar & & Lebih ... daripada & \\
\hline Di & Selama & & Sama ... dengan & \\
\hline Hingga & Sepanjang & & & \\
\hline Kecuali & Seputar & & & \\
\hline Lepas & Seuluruh & & & \\
\hline Lewat & Terhadap & & & \\
\hline Oleh & Bagaikan & & & \\
\hline Pada & Melalui & & & \\
\hline Per & Mengenai & & & \\
\hline Perihal & & & & \\
\hline Sampai & & & & \\
\hline Sejak & & & & \\
\hline Semenjak & & & & \\
\hline Seperti & & & & \\
\hline Serta & & & & \\
\hline Tanpa & & & & \\
\hline Tentang & & & & \\
\hline Untuk & & & & \\
\hline
\end{tabular}

Berdasarkan fungsinya, preposisi dalam bahasa Indonesia dijelaskan sebagai berikut.

\section{Penanda hubungan tempat}

Preposisi yang berfungsi sebagai penanda hubungan tempat adalah di, dalam, dan pada. Contoh kalimat:

(1) Dia tinggal di Bandung.

(2) Dalam pandangan lain, pernyataan dikap yang ini tidak hanya berlaku pada kriteria presiden.

(3) Arahnya mulai mengarah pada perdebatan mengenani sosok pemimpin nasional.

\section{Penanda hubungan arah}

Preposisi yang menandai hubungan arah adalah ke, dari, dari ... ke, kepada, dari ... kepada, menuju, sampai, dari ... hingga, dari.. sampai. Contoh kalimat:

(1) Ujung yang lain dimasukkan ke dalam gagang kayu.

(2) Dia berangkat dari rumahnya tepat pukul tujuh.

(3) Ia berjalan dari TPS ke TPS untuk memantau perhitungan suara.

(4) Daren meminjamkan uangnya kepada saya.

(5) Berita perolehan hasil penghitungan suara itu disampaikan dari KPPS kepada KPPI.

(6) Mereka baru berangkat menuju Jakarta.

(7) Sinar itu bisa menembus perut sampai belakang tubuh.

(8) Ia mengoceh terus dari Jakarta hingga Bandung.

(9) Dari rumah sampai knator ia bersenandung gembira. 


\section{Penanda hubungan peralihan}

Preposisi yang menandai hubungan peralihan adalah via, lewat, dan melalui. Contoh kalimat:

(1) Mereka akan ke Jakarta via Bandung.

(2) Ia berbicara lewat telepon genggam untuk menyampaikan berbagai kecurangan.

(3) Demi kerahasiaannya terpaksa ia menyampaikan berita itu melalui surat.

\section{Penanda hubungan perihal}

Preposisi yang menandai hubungan perihal adalah tentang, akan, perkara, perihal, menyangkut, dan mengenai. Contoh kalimat:

(1) Berbicara tentang emansipasi, wanita Indonesia belum dapat mengisi semua posisi yang sekarang dikuasai pria.

(2) Dia tahu betul akan maksudku.

(3) Sudahlah, perkara uang tak usah kaurisaukan.

(4) Dia belum paham betul perihal sifatnya.

(5) Jika parlemen melegalisasi semua vonis mati itu, akan timbul problema besar menyangkut hak asasi manusia.

(6) Apa yang dikeluhkannya mengenai diskriminasi pernah pula dirasakannya sendiri dalam berbagai pencalonan pemimpin organisasi.

\section{Penanda hubungan cakupan}

Preposisi yang menandai hubungan cakupan adalah meliputi dan sekitar. Contoh kalimat:

(1) Yang dijelankannya banyak sekali meliputi hukum dan etika.

(2) Benda itu berdiameter sekitar $12 \mathrm{~mm}$.

\section{Penanda hubungan sebab}

Preposisi yang menandai hubungan sebab adalah karena, sebab, berkat, oleh, oleh karena, lantaran, atas, dari, dengan, oleh sebab, lewat, melalui, akibat, gara-gara, dan perkara. Contoh kalimat:

(1) Saya berbuat begini karena kamu.

(2) Tina gagal mendapat beasiswa sebab terlambat mengirimkan berkas.

(3) Berkat keteguhan sikapnya, ia dipercaya rakyat.

(4) Oleh usaha temannya, dia berhasil masuk kelompok usaha itu.

(5) Oleh karena kebaikannya, kami berhasil emngatasi masalah itu.

(6) Bergabungnya PPP dengan Golkar bukan lantaran Golkar, tetapi karena Habibie.

(7) Atas usahanya sendiri dia lulus seleksi babak akhir.

(8) Hal itu dilakukannya dari kemauannya sendiri.

(9) Dengan kemampuannya sendiri ia lulus SBMPTN.

(10) Oleh sebab kekompakkannya yang tinggi, mereka berhasil menghadapi segala rintangan.

(11) Lewat kecerdasannya ia berhasil membangun rumah bercitra artistik tinggi.

(12) Melalui keteguhan sikapnya ia mampu mengatasi semua hujatan orang.

(13) Jerman menghimbau kepada masyarakat Kurdi untuk tetap menahan diri dari reaksi yang memuncak akibat putusan pengadilan Turki. 
(14) Gara-gara wanita, pekerjaannya berantakan.

(15) Kalian bertengkar hanya karena perkara wanita.

\section{Penanda hubungan persesuaian}

Preposisi yang menandai hubungan persesuaian adalah dengan dan menurut. Contoh kalimat:

(1) Menurut dia, itu memberi landasan wawasan yang sangat baik karen memiliki efek pendidikan demokrasi.

(2) Ini berkaitan dengan tradisi.

\section{Penanda hubungan alasan}

Preposisi yang menandai hubungan alasan adalah akan, pada, dan dari. Contoh kalimat:

(1) Menginat akan akibat yang akan timbul kemudian, kami memutuskan tidak jadi berangkat.

(2) PPI bertindak berdasarkan pada keputusan-keputusan KPU.

(3) Bertolak dari kenyataan itulah, saya berpendapat mereka perlu dibantu.

\section{Penanda hubungan pelaku}

Preposisi yang menandai hubungan pelaku adalah oleh. Contoh kalimat:

(1) Pandangan kelayakan perempuan memimpin jabatan publik itu tidak diungkapkan responden perempuan tetapi juga oleh responden laki-laki.

\section{Penanda hubungan cara dan kesertaan}

Preposisi yang menandai hubungan cara dan kesertaan adalahdengan, sambil, beserta, tanpa, dan bersama.

(1) Perginya disertai dengan teriakan ketidakpuasan.

(2) Dia terbiasa mengerjakan tugas sambil mendengarkan musik.

(3) Kirimkan lamaran anda beserta biodata lengkap.

(4) Para pemain tanpa ragu mengiris lidahnya dengan golok.

(5) Pada kesempatan berlaga di tahun 1999, Jerman berada di grup maut bersama Brazil, Meksiko, dan Italia.

\section{Penanda hubungan pembandingan}

Preposisi yang menandai hubungan pembandingan terdiri atas tiga kelompok, penanda hubungan penyamaan (seperti sama dengan, seperti, bagai, bak, bagaikan, laksana, serasa, dan ibarat), pembedaan (seperti daripada, ketimbang, dan tinimbang), dan penggolongan (seperti sebagai, semacam, sejenis, selaku, dan serupa). Contoh kalimat:

(1) Akan muncul lebih banyak seperti saya, tidak hanya satu PK tetapi puluhan.

(2) Keduanya sama betul, bagai pinang dibelah dua.

(3) Di sini saya merasa bak raja. 
(4) Bagaikan punguk merindukan bulan.

(5) Laksana rusa merindukan air, dia rindu sekali pada kekasihnya.

(6) Golok tajam berkelebatan ibarat dalam film silat.

(7) Namun yang dianggap sebagai pemimpin keluarga tetaplah laki-laki.

(8) Telah terjadi semacam usaha sistematis untuk pembatalan SU MPR.

(9) Burung sejenis itu sudah langka di habitatnya.

(10) Ocalan divonis mati bukan selaku pemimpin politik, akan tetapi sebagai pemimpin organisasi teroris.

(11) Pandangan serupa ini pernah dilontarkan oleh ketua NU.

(12) Serasa di atas angin mereka gembira sekali.

\section{Penanda hubungan waktu dan keberlangsungan}

Preposisi yang menandai hubungan waktu adalah sebelum, sesuah, setelah, sehabis, pada, hingga, sampai, sejak, semenjak, dan menjelang dan preposisi yang menandai hubungan keberlangsungan adalah sejak, sampai, semenjak, dari, sejak dari, sedari, mulai, mulai dari, sampai dengan, hingga, dan selama. Contoh kalimat:

(1) Sejak itu pikirannya terguncang.

(2) Semenjak saat itu, saya tidak terlibat lagi.

(3) Menjelang tengah malam ia baru kembali.

(4) Sebelum kejadaian itu ia tak tahu apa yang dilakukannya.

(5) Sesudah ketahuan ia baru jera.

(6) Sehabis makan malam ia meninggalkan rumah.

(7) Dia tinggal di Jepang selama lima tahun.

(8) Sampai dengan hari ini tak ada penjelasan resmi mengenai pembatalan status tersebut.

(9) Pada waktu itu kami belum menyadari apa maksudnya sesungguhnya.

(10) Hingga kemarin dia belum mengakui perbuatannya.

\section{Penanda hubungan tujuan}

Preposisi yang menandai hubungan tujuan adalah bagi, untuk, buat, guna, demi, dan agar. Contoh kalimat:

(1) Bahkan, bisa menembus perempat final akan merupakan sukses bagi semua tim.

(2) Biaya yang dikeluarkan tidak cuma untuk kebutuhan rumah tangga.

(3) Buat saya tak ada bedanya.

(4) Saya berusaha maksimal guna perbaikan nasib.

(5) Alasannya demi memudahkan pembagian waktu.

(6) Bukalah jendela agar sirkulasi udara terjaga.

\section{Penanda hubungan milik}

Preposisi yang menandai hubungan milik adalah dari. Contoh kalimat:

(1) Banyak orang yang berhak mendapat uang dari album itu. 


\section{Penanda hubungan asal}

Preposisi yang menandai hubungan asal adalah dari. Contoh kalimat:

(1) Dia berasal dari Kediri, Jawa Timur.

\section{Penanda hubungan sasaran}

Preposisi yang menandai hubungan sasaran adalah atas, terhadap, kepada, dan pada. Contoh kalimat:

(1) Putusan mati atas diri pemimpin Kurdi itu menimbulkan reaksi yang mendua.

(2) Pandangan responden terhadap peran laki-laki dan perempuan belum seluruhnya berubah.

(3) Demonstran itu mengajukan protes kepada wakil rakyat di DPR.

(4) Semua caci dan maki ditujukan pada wakil-wakil rakyat tersebut.

\section{Partikel Preposisi Bahasa Korea}

Bright Learning Center (2017) menyebutkan beberapa partikel dalam bahasa Korea sebagai berikut.

1. 에, 에게/한테, 께 [-e, -ege/hanthe, -kke]

에, 에게/한테, 께 berarti 'untuk, kepada'. Manusia dan hewan menggunakan partikel

‘ 에게/한테' sedangkan selain itu menggunakan partikel ' 에'.

(1) 칮구에선물을보냈어요.

Mengirimkan hadiah kepada teman.

(2) 동생한테편지를섰어요.

Aku telah menulis surat untuk adikku

(3) 벽에기대다.

Bersandar kepada tembok.

Partikel ' 께' adalah bentuk honorifik atau formal dari bentuk ' 에게/한테'

(1) 부모님께만씀을드렸습니다.

Saya sudah berbicara kepada orang tua.

Partikel ' 에' memiliki beberapa fungsi, yakni (1) menunjukkan tujuan, (2) menunjukkan kata benda yang menyatakan tempat atau kedudukan, (3) menyatakan sebuah kondisi jika dilekatkan dengan kata benda yang menunjukkan waktu, (4) menunjukkan sebab dari sebuah tindakan, (5) menunjukkan proporsi dan nilai. Berikut contoh kalimatnya:

(1) 동갱이학교에가요. 
Adik pergi ke sekolah.

(2) 이약은두통에좋아요.

Obat ini bagus untuk sakit kepala

(3) 내년 2 월에한국에가겠습니다.

Saya akan pergi ke Korea pada Februari tahun depan.

(4) 천둥소리에감짝놀랐어요.

Aku kaget karena suara petir.

(5) 하루에 2 번만밥을먹어요.

Dalam sehari hanya makan dua kali.

2. 에서, 에게서/한테서[-eseo, -egeseo/hantheseo]

에서, 에게서/한테서 berarti 'di, dari'. Partikel ' 에게서/한테서' berarti 'dari' digunakan pada kata benda yang menunjukkan manusia dan hewan. Contoh kalimat sebagai berikut:

(1) 친구에게서초대를받았어요.

Mendapat undangan dari teman.

(2) 새에게서소리가들어요.

Mendengar suara dari burung.

Partikel ' 에서' memiliki beberapa fungsi, yaitu (1) menunjukkan lokasi dilakukannya sebuah tindakan, (2) menyatakan titik atau tempat keberangkatan sementara, (3) berarti 'dari' bila dilekatkan pada kata benda selain manusia dan hewan, dan (4) menunjukkan tempat. Berikut contoh kalimatnya:

(1) 은행에서일해요.

Bekerja di bank.

(2) 인도네시아에서한국까지비행기로 8 시간을걸려요.

Dari Indonesia sampai Korea memerlukan delapan jam dengan pesawat.

(3) 그회사에서배운것이많아요.

Banyak hal yang dipelajari dari perusahaan itu.

(4) 학생들이교실에서공부합니다.

Murid-murid ada di kelas. 
3. $\sim($ 으)로 [-(eu)ro]

Partikel ' (으)로' berarti 'dengan, menggunakan, untuk, sebagai, ke'. Fungsi dasar dari partikel ' (으)로' adalah untuk menyatakan metode, alat dan cara dari sebuah tindakan. Contoh kalimat:

(1) 붓으로그림을그립니다.

Melukis menggunakan kuas.

(2) 자카르타에서서울까지비핸기로 7 시간을걸려료.

Dari Jakarta ke Seoul membutuhkan waktu tujuh jam dengan pesawat.

Partikel ' (으)로' memiliki beberapa fungsi lain, yaitu (1) menunjukkan arah, (2) menunjukkan sumber atau alasan, (3) menunjukkan tindakan, tingkah laku dan akhir dari sebuah proses, dan (4) menunjukkan status, posisi, kedudukan dan kemampuan manusia. Berikut contoh kalimatnya:

(1) 내년초에한국으로떠나가겠습니다.

Awal tahun depan aku akan pergi ke Korea.

(2) 회사일로스트레스를많니받아요.

Aku banyak mendapat stress karena pekerjaan kantor.

(3) 서로악수로인사를나눕니다.

Saling menyapa dengan berjabat tangan.

(4) 그분은병원에서의사로임해요.

Orang itu bekerja sebagai dokter di rumah sakit.

4. (으)로서[-(eu)roseo]

Partikel ' (으)로서' yang berarti 'sebagai' berfungsi untuk menunjukkan status, posisi, kemampuan dan kualifikasi. Contoh kalimat:

(1) 장여로서의책임을다해야지요.

Aku harus melakukan semua kewajiban sebagai putri sulung.

5. $\sim($ 으)로써 [-(eu)rosseo]

Partikel ' (으)로써' yang berarti ‘dengan, menggunakan, karena' berfungsi untuk menunjukkan alat dan cara. Contoh kalimat:

(1) 저풀은이낫으로써벨것이다.

Rumput itu tercabut dengan sabit ini.

(2) 나는거짓말로써친구를위로했다.

Aku telah menghibur teman dengan kebohongan. 
6. 부터[-butheo]

Partikel ' 부터' menunjukkan titik sementara keberangkatan atau permulaan. Partikel ini berarti 'dari, dimulai dari/dengan, lakukan hal pertama kali'. Contoh kalimat sebagai berikut:

(1) 내일부터취직해요.

Aku bekerja mulai besok.

(2) 태어나서부터예뻐요.

Dia cantik sejak lahir.

(3) 반대부터하지말고내말을좀들어요.

Jangan menentang dulu, dengarkan perkataanku.

7. 까지[-kkaji]

Partikel ' 까지' menunjukkan batasan luar dari suatu periode dan tempat. Partikel ini juga dapat menunjukkan bahwa muncul suatu kejadian yang tidak terduga. Partikel ' $\sim$ 까지' berarti 'sampai, sejauh, sepanjang jalan, dalam'. Berikut contoh kalimatnya:

(1) 성공할때까지돌아오지않겠어요.

Aku tidak akan kembali sampai aku sukses.

(2) 너까지나를믿지안하면누가나를믿겠어?

Siapa yang akan percaya jika kamu pun tidak mempercayaiku?

8. 부터... 까지[-butheo ... -kkaji]

Partikel pelengkap ' 부터... 까지' ini menunjukkan titik sementara saat sesuatu dimilai hingga titik akhir. Partikel ini berarti 'dari ... sampai'. Contoh kalimat:

(1) 저는오전에덟시부터오후다섯시까지근무하요.

Saya bekerja dari jam delapan pagi sampai lima sore.

(2) 저는내년초부터다음 년까지한국에있겠습니다.

Saya akan berada di Korea dari awal tahun depan hingga tahun tahun berikutnya.

9. 보다[-boda]

Partikel ini merupakan partikel pelengkap yang digunakan untuk membandingkan dua hal atau lebih. Partikel ' 보다' berarti 'daripada'.

(1) 오늘은너제보다더더운것겉아요.

Kelihatannya hari ini jauh lebih panas daripada kemarin. 
Tabel 2. Perbandingan Partikel Preposisi Bahasa Indonesia dan Bahasa Korea

\begin{tabular}{|c|c|c|}
\hline & Bahasa Indonesia & Bahasa Korea \\
\hline 1. Bentuk & $\begin{array}{l}\text { Dituliskan dalam bahasa Indonesia } \\
\text { dengan huruf abjad. Berupa kata yang } \\
\text { mendampingi kata benda, kata kerja, dan } \\
\text { kata sifat. } \\
\text { Contoh: di, ke, dari. }\end{array}$ & $\begin{array}{l}\text { Dituliskan dalam bahasa korea dengan huruf Hangeul. } \\
\text { Berupa partikel atau sejumlah bentuk yang penulisannya } \\
\text { dilekatkan pada kata yang mendasarinya. } \\
\text { Contoh: } \\
\text { 학교에(ke sekolah) } \\
\text { [hakkyo-e] } \\
\text { 회사에서(dari kantor) } \\
\text { [hoesa-eseo] }\end{array}$ \\
\hline 2. $\quad$ Posisi & $\begin{array}{l}\text { Partikel preposisi dalam bahasa Indonesia } \\
\text { mayoritas dituliskan di depan kata yang } \\
\text { diterangkan. } \\
\text { Contoh: } \\
\text { oleh kakak } \\
\text { bak raja }\end{array}$ & $\begin{array}{l}\text { Preposisi dalam bahasa Korea dituliskan lekat dibelakang } \\
\text { kata yang diterangkan. } \\
\text { Contoh: } \\
\text { 한국으로(ke Korea) } \\
\text { [hanguk-euro] } \\
\text { 부모님께(kepada orang tua) } \\
\text { [bumonim-kke] }\end{array}$ \\
\hline 3. Fungsi & $\begin{array}{l}\text { Partikel preposisi dalam bahasa Indonesia } \\
\text { memiliki } 16 \text { fungsi, yaitu menyatakan } \\
\text { hubungan tempat, hubungan arah, } \\
\text { hubungan peralihan, hubungan perihal, } \\
\text { hubungan cakupan, hubungan sebab, } \\
\text { hubungan persesuaian, hubungan alasan, } \\
\text { hubungan pelaku, hubungan cara dan } \\
\text { kesertaan, hubungan pembandingan, } \\
\text { hubungan waktu, hubungan tujuan, } \\
\text { hubungan milik, hubungan asal dan } \\
\text { hubungan sasaran. Masing-masing fungsi } \\
\text { memiliki kata yang mewakilkannya } \\
\text { sendiri. } \\
\text { Contoh: } \\
\text { Fungsi hubungan pelaku. Kata oleh. } \\
\text { Fungsi hubungan asal. Kata dari. } \\
\text { Terdapat beberapa fungsi partikel } \\
\text { preposisi bahasa Indonesia yang tidak } \\
\text { muncul dalam partikel preposisi bahasa } \\
\text { Korea, yakni fungsi menyatakan } \\
\text { hubungan peralihan, hubungan perihal, } \\
\text { hubungan cakupan, hubungan persesuaian } \\
\text { dan hubungan pelaku. }\end{array}$ & $\begin{array}{l}\text { Partikel preposisi dalam bahasa Indonesia hanya terdapat 11, } \\
\text { yakni fungsi menyatakan hubungan tempat, hubungan arah, } \\
\text { hubungan sebab, hubungan cara dan kesertaan, hubungan } \\
\text { perbandingan, hubungan waktu, hubungan tujuan, hubungan } \\
\text { milik, hubungan asal dan hubungan sasaran. } \\
\text { (1) Partikel preposisi } \\
\text { 에, 에게/한테, 께 memiliki fungsi menyatakan hubungan } \\
\text { tempat, hubungan arah, hubungan sebab, hubungan waktu, } \\
\text { hubungan tujuan dan hubungan sasaran. } \\
\text { Contoh: } \\
\text { 벽에기대다. } \\
\text { Bersandar kepada tembok. } \\
\text { 부모님께만씀을드렸습니다. } \\
\text { Saya sudah berbicara kepada orang tua. } \\
\text { 내년 } 2 \text { 월에한국에가겠습니다. } \\
\text { Saya akan pergi ke Korea pada Februari tahun depan. } \\
\text { 천둥소리에감짝놀랐어요. } \\
\text { Aku kaget karena suara petir. } \\
\text { (2) Partikel preposisi 에서, 에게서/한테서 memiliki } \\
\text { fungsi menyatakan hubungan tempat, hubungan arah, } \\
\text { hubungan waktu, hubungan milik dan hubungan asal. } \\
\text { Contoh: } \\
\text { 은행에서일해요. } \\
\text { Bekerja di bank. } \\
\text { 인도네시아에서한국까지비행기로 } 8 \text { 시간을걸려요. } \\
\text { Dari Indonesia sampai Korea memerlukan delapan jam } \\
\text { dengan pesawat. } \\
\text { (3) Partikel preposisi (으)로 memiliki fungsi menyatakan } \\
\text { 붓으로그림을그립 니다. } \\
\text { Melukis menggunakan kuas. } \\
\text { kesertaan dan hubungan pembandingan. } \\
\text { (a) }\end{array}$ \\
\hline
\end{tabular}




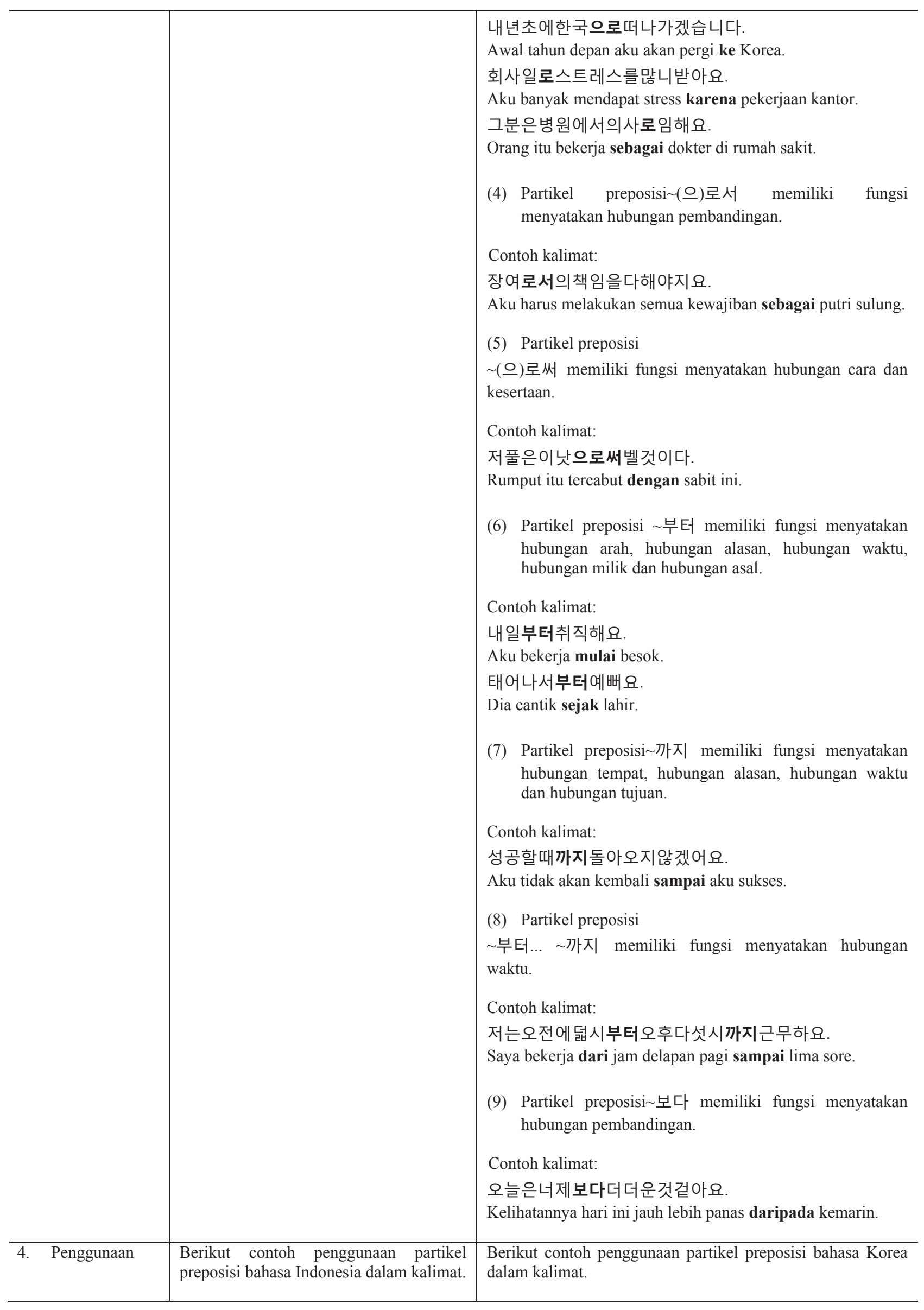




\begin{tabular}{|c|c|c|}
\hline & $\begin{array}{l}\text { Contoh: } \\
\text { Dia tinggal di Jepang selama lima tahun. } \\
\text { Biaya yang dikeluarkan tidak cuma untuk } \\
\text { kebutuhan rumah tangga. } \\
\text { Arahnya mulai mengarah pada } \\
\text { perdebatan mengenani sosok pemimpin } \\
\text { nasional. }\end{array}$ & $\begin{array}{l}\text { Contoh: } \\
\text { 저는내년초부터다음년까지한국에있겠습니다. } \\
\text { [Jeoneun naenyeoncho-butheo daeumnyeon-kkaji hanguk-e } \\
\text { itgesseumnida.] } \\
\text { Saya akan berada di Korea dari awal tahun depan hingga } \\
\text { tahun tahun berikutnya. } \\
\text { 동생한테편지를섰어요. } \\
\text { [Dongsaeng-hante pyeonjireul seosseoyo.] } \\
\text { Aku telah menulis surat untuk adikku } \\
\text { 나는거짓말로써친구를위로했다. } \\
\text { [Naneun kojitmal-losseo chingureul wiro haetda.] } \\
\text { Aku telah menghibur teman dengan kebohongan. }\end{array}$ \\
\hline
\end{tabular}

\section{PENUTUP}

Dari data yang telah dianalisis dapat disimpulkan bahwa persamaan dan perbedaan Partikel Preposisi bahasa Indonesia dengan bahasa Korea sebagai berikut.

1. Bentuk partikel preposisi dari kedua bahasa berbeda. Bahasa Indonesia partikelnya berupa kata sedangkan bahasa korea partikelnya berupa satuan yang lekat atau morfem

2. Posisi partikel preposisi dalam bahasa Indonesia umumnya terdapat di depan kata yang diterangkan sedangkan partikel preposisi dalam bahasa Korea pasti lekat dibelakang kata yang diterangkannya.

3. Fungsi partikel preposisi dalam bahasa Indonesia berjumlah 16 sedangkan fungsi partikel preposisi dalam bahasa Korea berjumlah 11 .

4. Penggunaan partikel preposisi dalam kedua bahasa sama-sama berperan aktif dalam pembentukan kalimat.

\section{DAFTAR PUSTAKA}

Bright Learning Center. 2017. Simple Fun and Easy Percakapan Bahasa Korea. Yogyakarta: Bright Publisher.

Chaer, Abdul. 2015. Morfologi Bahasa Indonedia: Pendekatan Proses. Jakarta: Rineka Cipta.

Fries, C. Charles. 1945. Teaching and Learning English as a Foreign Language. Ann Arbor: University of Michigan Press.

Kentjono, D., dkk. 2010. Tata Bahasa Acuan Bahasa Indonesia untuk Penutur Asing. Jakarta: Penerbit Wedatama Widya Sastra.

Lado, Robert. 1957. Linguistics Across Cultures. Ann Arbor: The University of Michigan Press. 